\title{
Botulism...Or Is It?
}

\author{
Erica A. Miller, DVM ${ }^{1}$, Emily Brunner ${ }^{2}$, Cindy Driscoll, DVM ${ }^{3}$, and Peter McGowan 4

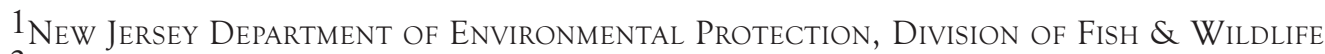 \\ ${ }^{2}$ Tri-State Bird Rescue \& Research, Inc., Newark, Delaware \\ ${ }^{3}$ Maryland Department of Natural Resources \\ ${ }^{4}$ US Fish \& Wildlife SeRVice
}

\begin{abstract}
In August 2012, during routine surveys of Poplar Island, MD, shorebirds and ducks were found in varying stages of paralysis. Some birds were 'wing walking,' others could barely hold up their heads, some had lost function of the nictitans, and many more were dead. These clinical signs, combined with the location, climate, and water conditions, were highly suggestive of avian botulism. As biologists from the US Fish \& Wildlife Service teamed with the MD state wildlife veterinarian, Maryland Environmental Service, and staff and volunteers from Tri-State Bird Rescue \& Research to capture and care for the affected birds, laboratory tests suggested something besides botulism might be present. This presentation describes the combined efforts of these groups and six separate laboratories to unravel the mystery of this epornitic and to provide treatment to those birds rescued live.
\end{abstract}

Key words: Botulism, Clostridium botulinum-Type C, Harmful Algal Bloom (HAB), microcystins, avian toxicoses, Poplar Island MD, blue-green algae (Cyanobacteria), phycotoxins, cyanotoxins

\section{BACKGROUND}

Poplar Island Ecosystem Restoration. Poplar Island lies in the Chesapeake Bay, about 34 miles (54 km) south of Baltimore, MD and west of Washington, DC. One hundred and fifty years ago, the main island was over 1000 acres, but erosion and rising water levels fragmented the land mass into several small islands, with this "main island" being reduced to 10 acres by 1990 (Figures 1 and 2). A 30-year Restoration Project (the Paul S. Sarbanes Ecosystem Restoration Project)

Erica Miller is a wildlife veterinarian with the New Jersey Division of Fish \& Wildlife. She is a past president and former board member of NWRA.

Emily Brunner is a Clinic Supervisor at Tri-State Bird Rescue \& Research, Inc., in Newark, DE. She has a B.S. in Zoology and has been rehabilitating wildlife for three years.

Cindy Driscoll has been the wildlife veterinarian with the Maryland Department of Natural Resources for 15 years and University of Maryland, Wildlife Diseases course coordinator and instructor for 20 years.

Peter McGowan is a wildlife biologist for the US Fish and Wildlife Service's Chesapeake Bay Field Office in Annapolis, Maryland. He has been responsible for wildlife management activities at the Paul S. Sarbanes Ecosystem Project at Poplar Island for the past eight years. begun in 1998 is reconstructing Poplar Island to its former size and ecological function using uncontaminated dredged material from the Baltimore Harbor. The restoration of the island involves placing, shaping, and planting approximately 68 million cubic yards of dredged material to create 1,715 acres of wetland, upland, and open water habitat. Of the wetland areas, 80 percent is being developed as low marsh and 20 percent as high marsh. Small upland islands, ponds, and dendritic channels are being created to increase habitat diversity within the marsh areas. Habitat diversity is being increased in the upland areas by constructing small ponds and providing both forested and relatively open scrub/shrub areas. Since the restoration began, more than 170 bird species have been recorded at Poplar Island, 25 of which have been nesting.

Event History. On 2 August 2012, during routine monitoring on the island, US Fish \& Wildlife Service (USFWS) biologists found three decomposing carcasses and a black-necked stilt (Himantopus mexicanus) in Cell 5CD that was weak and sternal (Figure 3). The bird was transferred to Tri-State Bird Rescue \& Research (Tri-State) in Newark, DE, where a presumptive diagnosis of botulism was made based on the clinical signs and the history of previous avian botulism events on the island since 2004 . Temperatures in the area had been in the mid-80 to 90 degrees $\mathrm{F}\left(27-32^{\circ} \mathrm{C}\right)$, above normal, with rainfall below normal (NOAA), resulting in low water levels. These climatic conditions are conducive to a botulism event (Rocke and Bollinger 2007). Having dealt with botulism events in the past, the USFWS set up daily surveys of the island; Tri-State worked with USFWS and Maryland Environmental Services (MES) personnel to coordinate transportation of affected birds to Tri-State. Staff and volunteers from USFWS, MES, and Maryland Department of Natural Resources 


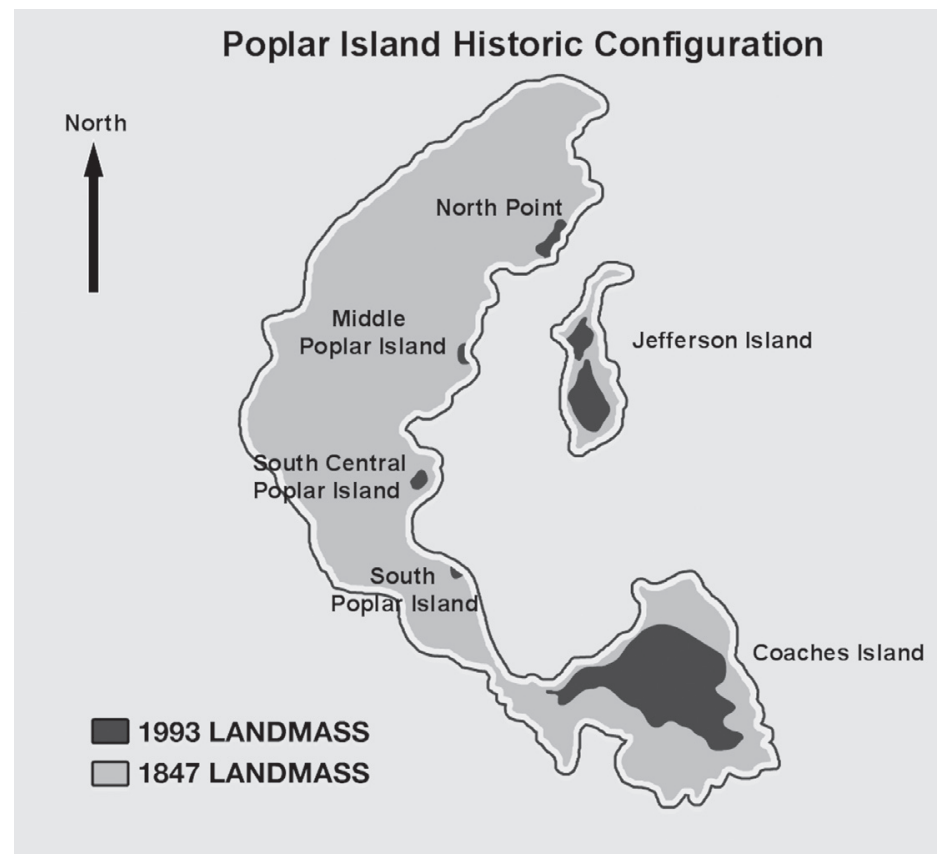

Figure 1. Image showing Poplar Island land mass in 1847 vs. reduced 1993 land mass.

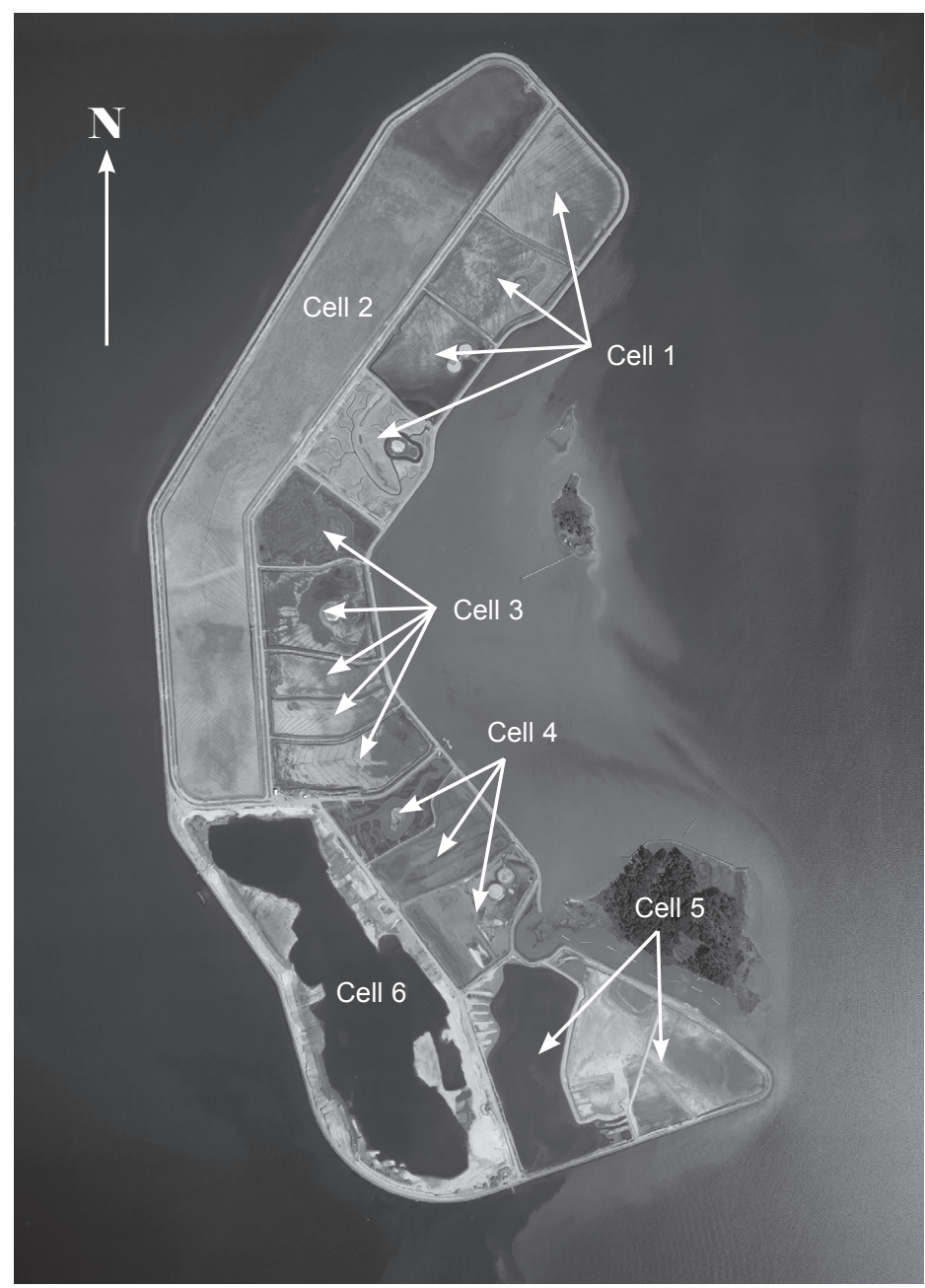

Figure 2. Map of Poplar Island depicting the restoration cells.
(DNR) began surveying the cells for sick or dead birds. Surveys consisted of walking shorelines and checking the vegetation where sick birds were likely to retreat. Site personnel were notified that a botulism event could be in the early stages and were requested to report any birds they observed exhibiting behaviors that did not appear normal, (i.e., weak, no effort to move when approached, heads kept low), as well as dead birds along shorelines or floating in the water. Because a definitive diagnosis had not been confirmed, precautions included using gloves when handling sick or dead birds and burying of any carcasses found.

The island is a twenty-minute boat ride from Tilghman Island, which in turn is a two-hour drive from Tri-State. Volunteer transporters from Tri-State met the boat and either took the birds all the way to Tri-State or relayed the birds at a midpoint. Surveys by USFWS and MES and bird transfers continued almost daily for two weeks, then tapered to three times per week, and eventually weekly until the last sick bird was retrieved on 26 October. A total of 37 such trips were made to deliver 188 birds to Tri-State.

Treatment on the Island. Of the first large delivery of 18 live birds, 10 died within 12 hours of arriving at Tri-State. The possibility of many more birds being affected and having to undergo the long transport time prompted Tri-State to contact Dr. Cindy Driscoll, Wildlife Veterinarian for Maryland DNR. Tri-State sent gavage supplies (syringes and tubes) and ophthalmic lubricant to Poplar Island. After assisting with field surveys, Dr. Driscoll showed MES staff and volunteers how to begin stabilizing the birds while still on the island. When possible, birds were gavaged clear fluids (water or Pedialyte ${ }^{\circledR}$, Abbott Laboratories, Abbott Park, IL) and placed in boxes with towels supporting their heads. The boxes were kept in a quiet area, out of the heat, until the daily transportation took place.

Presentation to Tri-State. Birds from Poplar Island arrived at Tri-State in four different states: Stages I through III (as described by Hunter et al 1970) and Dead:

- Stage I: Birds that could not fly, but were still alert and attempting to "wing-walk." These birds were considered to be mildly affected.

- Stage II: More seriously affected birds that exhibited leg paralysis and could not walk; these birds were not self-feeding on entry, 


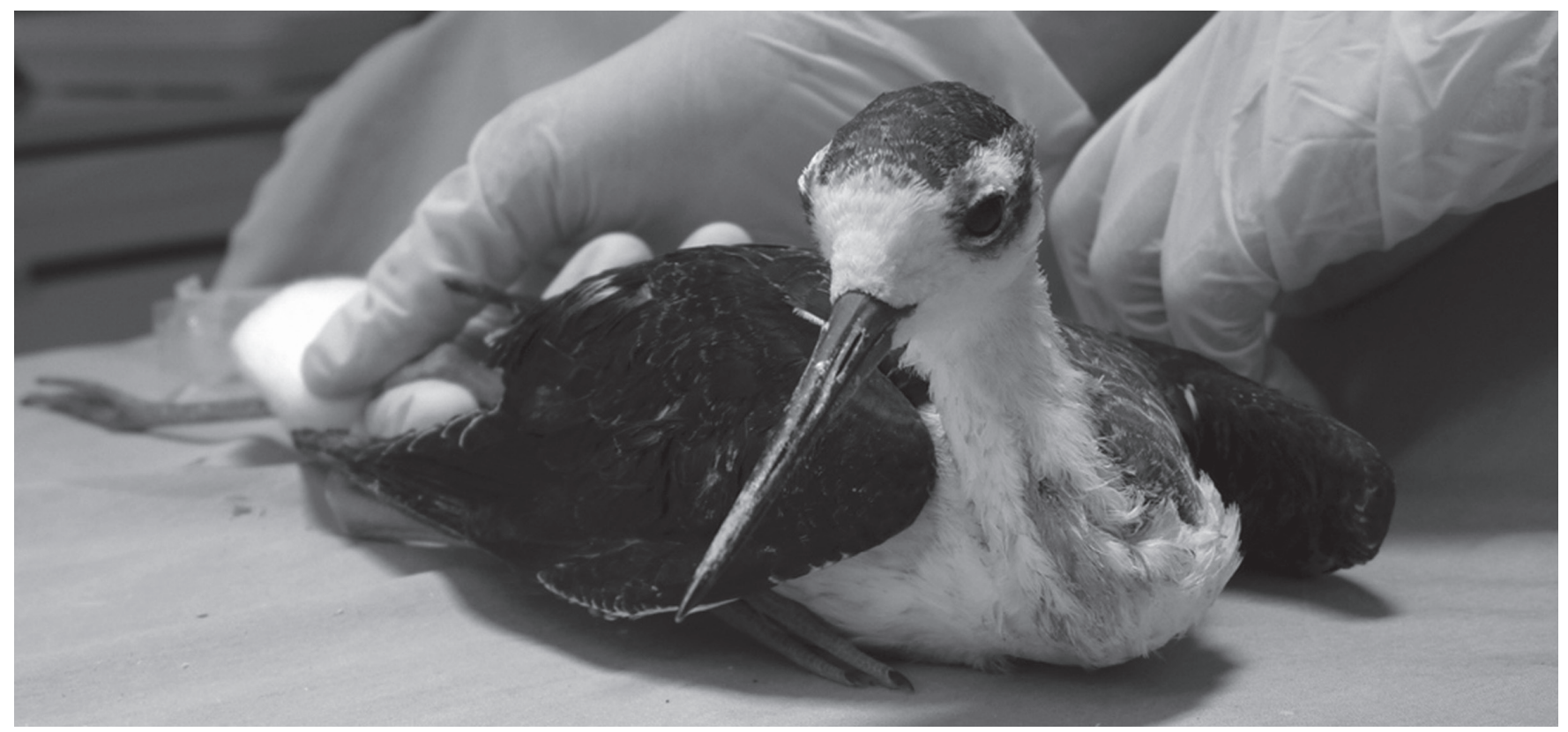

Figure 3. Black-necked stilt (Himantopus mexicanus) on admit exam. This bird was the sentinel case for this event.

and while they could hold their heads up, they often drooped their heads at rest and possessed a slow nictitans.

- Stage III: Critically ill birds that had almost complete paralysis of the legs and wings, could not hold up their heads or retract their nictitating membrane, and showed little response to external stimuli. Based on the poor survival rate of Stage III birds seen in the early weeks of the event, Stage III birds received later in the response were euthanized on arrival.

- Dead: These birds either were dead on arrival (DOA) or died in the few minutes between arrival and the time the admission exam began (died before admission or DBA). Twenty-seven of the 188 birds sent to Tri-State (>14 percent) were DOA/DBA. An additional 25 birds (12\% of the 213 birds found alive) died before leaving the island; these birds were not sent to Tri-State.

'Typical' Botulism. Botulism neurotoxins are the most acutely toxic substances known. Avian botulism is one of the most significant causes of mortality in migratory birds in North America, resulting in the deaths of 5000 to 14,000 birds annually (Cubas 1993). It is caused by exposure to botulinum toxin, produced by the gram-positive bacterium, Clostridium botulinum. Although there are seven known types of botulinum toxin (classified as types A through $\mathrm{G}$ ), types $\mathrm{C}$ and $\mathrm{E}$ are the only strains known to affect birds. Waterfowl, particularly mallards (Anas platyrhynchos), wood ducks (Aix sponsa), and teal (Anas spp.) are historically the species most sensitive to type $\mathrm{C}$ botulism, though shorebirds, herons, and gulls also commonly are affected and all vertebrates are susceptible. Outbreaks usually occur in late July through September, when water levels are low; the shallow water warms more easily, creating an environment more conducive to bacterial growth. Normally, the bacterium exists as a dormant spore in freshwater habitats; however, in favorable conditions in low oxygen (anaerobic) environments, the spores germinate into active bacteria, multiply, and produce toxin. Favorable conditions consist of water $\mathrm{pH} 5.7$ to 6.2, depending on the amount of protein in the substrate, and high ambient temperatures of at least $25^{\circ} \mathrm{C}\left(77^{\circ} \mathrm{F}\right)$, with optimal growth around $40^{\circ} \mathrm{C}$ $\left(104^{\circ} \mathrm{F}\right)$ (Segner et al 1971; Rocke and Bollinger 2007). Toxin may be produced by bacteria in the anaerobic environment found in detritus, or in rotting carcasses of affected birds. Because the growth conditions are actually better in carcasses (higher protein), the toxin produced in carcasses is usually considerably more potent than the toxin produced in soil or detritus (Rocke and Bollinger 2007). Like type D botulism, type $\mathrm{C}$ only can produce toxin when infected with a specific bacteriophage (a virus that infects bacteria). The toxin is produced during the growth phase of the bacteria, and is released when the bacteria die and rupture (autolyze). Birds can pass active toxin in their feces for up to 48 hours after ingestion (Jensen 1981). Fortunately, humans are not thought to be susceptible to type $\mathrm{C}$ toxin (Rocke and Bollinger 2007). Carcasses from dead birds attract flies that are abundant in warm weather and a single carcass may 
Table 1. Chart depicting amounts of fluids and treatments given to affected birds.

\begin{tabular}{|c|l|l|l|l|}
\hline & \multicolumn{1}{|c|}{ Admit } & \multicolumn{1}{c|}{ Day 1 } & \multicolumn{1}{c|}{ Day 2 } & \multicolumn{1}{c|}{ Day 3 } \\
\hline Stage 1 & $\begin{array}{l}\text { SQ/IV fluids } \\
\text { Pedialyte 2x }\end{array}$ & $\begin{array}{l}\text { SQ/IV fluids } \\
\text { E/Pedia QID }\end{array}$ & $\begin{array}{l}\text { Evaluate for SQ/IV fluids } \\
\text { E QID }\end{array}$ & Re-evaluate case \\
\hline \multirow{3}{*}{ Stage 2 } & $\begin{array}{l}\text { SQ/IV fluids 1.5\% } \\
\text { Pedialyte 3x } \\
\text { Check eyes 3x }\end{array}$ & $\begin{array}{l}\text { SQ/IV fluids } \\
\text { E/Pedia Q2hrs } \\
\text { Check eyes Q2hrs } \\
\text { Check vent QID }\end{array}$ & $\begin{array}{l}\text { Evaluate for SQ/IV fluids } \\
\text { E Q2 or 3hrs } \\
\text { Check eyes Q2 or 3hrs } \\
\text { Check vent QID or TID }\end{array}$ & $\begin{array}{l}\text { Evaluate for SQ/IV fluids } \\
\text { E Q3hrs } \\
\text { Re-evaluate eyes } \\
\text { Re-evaluate vent } \\
\text { Re-evaluate case PRN }\end{array}$ \\
\hline \multirow{3}{*}{ Stage 3 3} & $\begin{array}{l}\text { SQ/IV fluids } \\
\text { Pedialyte 3x } \\
\text { Check eyes 3x }\end{array}$ & $\begin{array}{l}\text { Pedia or E/Pedia } \\
\text { Q2hrs } \\
\text { Check eyes Q2hrs } \\
\text { Check vent QID }\end{array}$ & $\begin{array}{l}\text { Evaluate for SQ/IV fluids } \\
\text { E/Pedia Q2hrs } \\
\text { Check eyes Q2 } \\
\text { Check vent TID }\end{array}$ & $\begin{array}{l}\text { Evaluate for SQ/IV fluids } \\
\text { E2 or 3hrs } \\
\text { Check eyes Q2 or 3hrs } \\
\text { Check vent TID or BID }\end{array}$ \\
\hline
\end{tabular}

SQ $/$ IV fluids $=3 \%$ of body weight; Gavage Diet $=1.5 \%$ of body weight; Pedia $=$ Pedialyte ${ }^{\circledR} ;$ E $=$ Emeraid ${ }^{\circledR}$ Omnivore or Carnivore diet

have several thousand maggots on it. Maggots (like all invertebrates) are not susceptible to C. botulinum toxin; they concentrate the toxin as they feed on affected carcasses, and ingestion of as few as two of these maggots can kill a mallard (Rocke and Friend 1999; Forbes 1996). Botulinum toxin remains stable in the carcasses and surrounding sediment, and bacterial spores in the environment may remain dormant yet viable for years. Removal of carcasses (and thus maggots) is essential to the control of any botulism event.

Once ingested by a vertebrate, the toxin is absorbed from the gastrointestinal (GI) tract and binds to the nerve cell membranes and inactivates proteins, which in turn prevents the release of the neurotransmitter acetylcholine. Blocking acetylcholine prevents nerve impulse transmission, resulting in flaccid (sagging) paralysis of striated muscles. This paralysis is dose related: the more toxin ingested, the fewer signals reaching the muscles and the weaker the animal becomes. This reaction also is irreversible: once bound to the nerve-muscle junction, the nerve ending is damaged and must be replaced before nerve transmission can occur. Thus, full recovery may take days to weeks, depending on the amount of toxin ingested and the duration of exposure.

\section{Botulism Treatment Overview. Tri-State's} protocol for admission exam and treatment of botulism birds was developed in the mid-1980s, based largely on protocol developed by Betsy Jones (1984). Details are discussed below; the basic approach centers around gavaging the affected birds with activated charcoal (AC; Toxiban ${ }^{\circledR}$, Lloyd, Inc., Shenandoah, IA) and numerous fluid boluses. AC has been shown to bind with botulinum toxin (Gomez et al 1995). The risk of aspiration is high, so $\mathrm{AC}$ is not given to birds that are not able to hold up their heads. The repeated oral fluid boluses flush the toxin from the gastrointestinal tract, as well as help to maintain hydration. If available, anti-toxin can be given to inactivate toxin that is absorbed into the blood, but the cost and logistics of obtaining the anti-toxin usually prevent its use in wildlife rehabilitation. These treatments prevent the clinical condition from getting worse. Supportive treatment to recovery may take days or weeks and involves keeping the bird hydrated and fed while the nerve terminals regenerate. However, with prompt and intensive treatment, many animals do recover completely.

\section{BIRD CARE AT TRI-STATE}

Admission and Initial Treatment. Due to travel logistics, birds usually arrived between 3 and 4 PM each day. After the first few deliveries, teams of two or three people were set up to admit the botulism birds each day. When possible, two people conducted the admission exams, while one person would transcribe, organize and run bloodwork, and complete the paperwork that accompanied each case.

Admissions were stream-lined by drawing up Toxiban ${ }^{\circledR}$ and fluids in advance of the birds' arrival. Each day Tri-State received a call from someone on Poplar Island stating the number of birds of each species that were being sent. Occasionally last-minute captures would be added, so two or three extra syringes of fluids were prepared daily. The appropriate number of leg tags, care charts, admission sheets, hematocrit tubes, needles, clay trays, eye flush syringes and triple antibiotic ophthalmic ointment or paralube, and gavage tubes also were prepared. Finally, the appropriate number of cages were set up in anticipation of the arrivals. 
On arrival, birds were removed from their transport boxes, weighed, and evaluated quickly to determine the Stage of their condition; small blood samples were collected from the waterfowl. Depending on stage of illness, birds received some or all of the following (Table 1):

- eyes rinsed and lubricated

- intravenous (IV) or subcutaneous (SQ) fluids

- oral Toxiban ${ }^{\circledR}$ and oral Pedialyte ${ }^{\circledR}$

- vents cleaned and Preparation- $\mathrm{H}^{\circledR}$ (Pfizer, Inc., New York, NY) applied.

Initial examination and treatment was completed in less than 10 minutes for waterfowl and in two to three minutes for small shorebirds, barring unforeseen issues like fractures or maggots. Advance preparation not only helped process birds efficiently, but also minimized stress. Minimizing external stresses is critical when treating birds affected by botulism, as the toxin causes them to be hypersensitive to stimuli while unable to respond due to paralysis.

Once admitted, most of the birds had two hours to settle into their enclosures before their second round of gavaged Pedialyte ${ }^{\circledR}$. The frequency of gavaging, eye treatments, and SQ/IV fluids on the day of admit was dependent on the incoming Stage: most birds, with the exception of those in Stage I, were gavaged at least three times on the day of admit.

Paralysis of the eyelids had to be closely monitored from the time of admit. If the nictitans had minimal to no response, eyes were checked for dryness every two hours, flushed, and lubricated as needed. Most birds with eye trouble had to be gavaged every twohours as well, so no extra disturbance was necessary. The frequency of eye checks was reduced gradually as they began to blink again. In most cases, it only took two to three days for the eyelids to begin functioning normally.

All birds, regardless of Stage, received SQ or IV fluids twice daily on the first full day. The vast majority were dehydrated due to paralysis in the hot ambient temperatures on the island, followed by the long trip to northern Delaware.

Nutrition. On their first full day at Tri-State, birds in Stage III were gavaged 50 percent Pedialyte ${ }^{\circledR}$ and 50 percent critical care diet, Emeraid ${ }^{\circledR}$ Carnivore for shorebirds and Emeraid ${ }^{\circledR}$ Omnivore or cereal diet for waterfowl, every two hours (Emeraid ${ }^{\circledR}$ Carnivore and Emeraid ${ }^{\circledR}$ Omnivore, Lafeber Company, Cornell, IL). Birds were evaluated at each treatment and were kept on straight Pedialyte ${ }^{\circledR}$ longer if they continued to show signs of Stage III. The same diet ratio and amount was tubed to Stage II birds every three hours and four times daily for Stage I birds. Each bird was carefully monitored and adjustments were made accordingly if there were signs of improvement or backsliding.

Birds which steadily improved were weaned off gavage feedings gradually and offered food, a process that took from two days to more than a week. The shorebirds and mallards self-fed much more readily than did Northern shovelers (Anas clypeata) and teal.

To encourage self-feeding, food was offered to waterfowl as soon as they had full control of their heads and necks and were wing- or hock-walking, and to shorebirds as soon as they were standing. Shorebirds were started on a mixture of frozen cubes of bloodworms, mysis shrimp, brine shrimp, freezedried tubifex worms, and a sprinkling of frozen two-week-old crickets in a shallow dish of water. Freeze-dried bloodworms were offered as well, but rarely were eaten until the birds were self-feeding consistently on other foods. Shallow trays with a thin layer of Mazuri ${ }^{\circledR}$ Insectivore Diet (PMI Nutrition, St. Louis, MO) or game bird starter crumbles (Southern States All-Grain Poultry Starter [non-medicated], Richmond, VA) were offered with a few live mealworms sprinkled on top. Small shallow dishes were preferable because the shorebirds often would be very unstable on their feet, even after they started walking, and if they tripped and fell into deeper food dishes, the feathers would become soiled. Most shorebirds started self-feeding almost immediately, usually starting with crickets, bloodworms, or live mealworms. One dunlin (Calidris alpina), however, only ate live mealworms.

Mallards first were offered a thin mixture of greens and gruel composed of a small handful of dissolved duck pellets with chopped romaine floating on top. Once the birds started eating this and appeared to be processing the food well, they were given duck pellets with a sprinkling of cracked corn. In addition to gruel and duck pellets, American black ducks (Anas rubripes) and shovelers were offered a dish of the same invertebrates offered to shorebirds, plus krill, mealworms, and occasionally small silverside fish for the black ducks. Teal were offered Mazuri ${ }^{\circledR}$ Waterfowl Starter (PMI Nutrition, St. Louis, MO) instead of duck pellets due to the higher protein content and smaller size of this diet. Live mealworms were mixed into the dry pellets to encourage self-feeding, then discontinued once the birds were eating well. 
Housing. Initially, birds were housed in three rooms in a quiet, isolated area of the building. Each room held tables for bird baskets and supplies, and as many playpens as space allowed. A set of routine medical supplies was placed in each room: containers of cotton-tipped applicators, cotton balls, eye flush and lubricant, and extra needles for SQ/IV fluids.

Each room also had a Daily Care Sheet that was updated every evening after the last round of gavage feedings (Figure 4). This sheet included case number and species, columns for every two-hour gavage and treatment, and columns for the exact time the tubing was done with initials of the caretaker. As each person entered the room to start gavaging s/he would do so in the same order as the previous person, thus the time between tubings for each bird would be as close to the correct time interval as possible. The order was particularly important when large numbers of birds were in care and a single round of treatments would take nearly two hours to complete.
Most mallards, black ducks, shovelers, and teal were housed in modified baby playpens. Each playpen had padding on the bottom, covered with a plastic sheet or bag, a thick layer of newspaper, and a bed sheet. One to five ducks were housed in each playpen if they were Stage II or III and could not injure one another. The more alert birds were kept two or three to a playpen as long as they did not fight.

On completion of their admission exam and treatment, most of the shorebirds were placed in plastic laundry baskets lined with soft netting, draped with a pillowcase to act as a visual barrier, and with newspaper and a pillowcase on the floor. The baskets worked very well for the killdeer and other shorebirds until they started to walk, fly, and self-feed. At that point, the birds were moved into playpens or into an outdoor enclosure. Usually, they were moved straight outside unless there was an ongoing weight issue or secondary illness requiring closer monitoring and/or treatment.

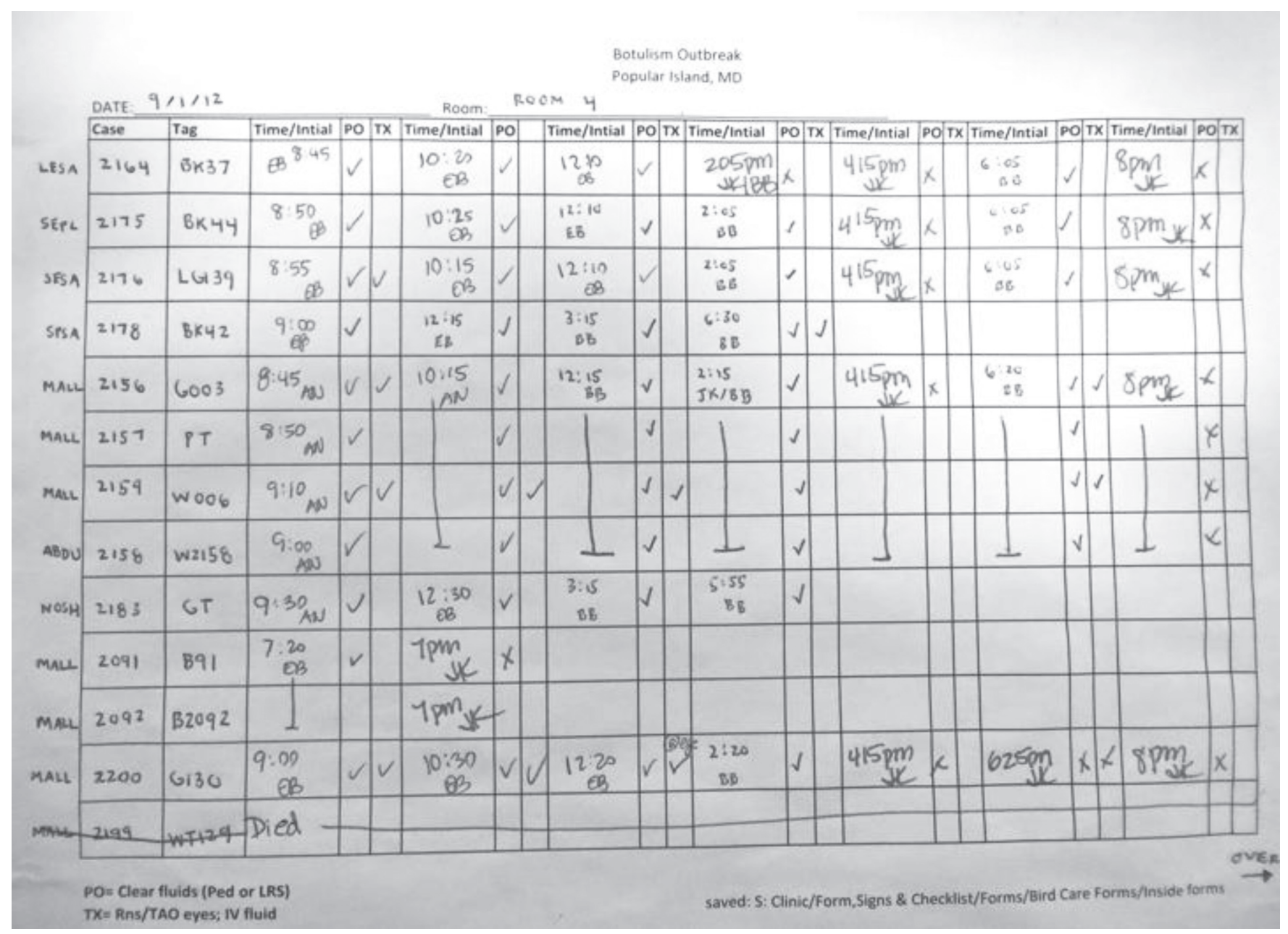

Figure 4. Daily care sheet used during this event. 
Many of the incoming birds were depressed and very weak, so they were placed on a heating pad the first day. Long, flat farrowing pads (Osborne Industries, Inc., Osborne, $\mathrm{KS}$ ) were placed under one half of each basket; a small heating pad (or two) was placed on the floor of each playpen, under the sheet.

Birds housed alone received a mirror for company. The mirrors appeared to help most waterfowl and shorebirds' overall attitude and readiness to self-feed due to their social nature. A few shorebirds, however, had a tendency to become so distracted by the mirror that they ignored the food and self-feeding actually was delayed.

\section{Water Access and Pools.}

Because nearly all the birds were shorebirds or waterfowl (two gulls also were affected), water was a key part of the husbandry and rehabilitation. All shorebirds and waterfowl in Stage I or II were spritzed lightly three times per day. Any waterfowl that started walking and appeared bright, alert, and responsive were given short, shallow swims twice daily.

Tri-State's hydrotherapy room contains one 54-gallon oval acrylic tub and one 50-gallon rectangular stainless steel tub (Figure 5). Three mallards or black ducks can swim comfortably in the large tub and one or two teal or shovelers can swim together in the steel tub. At the busiest time of this event, ducks were being swum twice daily for about 30 minutes each swim, occupying both tubs for a full eight hours.

The initial protocol was to wait until waterfowl started walking to start the swimming. However, some birds that were not walking yet were accumulating feces around their vents, so the decision was made to provide shallow, supervised swims for short periods of time. Regular swims kept the birds much cleaner and seemed to help their overall attitude greatly; many birds that were depressed and lethargic perked up significantly once placed in the tub. Most birds could

paddle before they could walk, allowing them to exercise, thus birds that started swimming earlier often started walking earlier.

The three main secondary problems encountered on admission or during rehabilitation of the birds with botulism were maggots, giardia, and poor feather condition.

Most of the Stage II and III birds had droppings caked on the vent skin and feathers at the time of admit. Many had severely irritated vents caused by adherent droppings. The vent area of these birds was 
washed during the admit exam. The hot weather meant that flies on Poplar Island were plentiful, which in turn meant several birds had fly eggs and maggots in the feathers. After cleaning away as many droppings and maggots as possible, the vent entrance and surrounding skin was flushed with dilute Capstar ${ }^{\mathrm{TM}}$ (nitenpyram, Novartis Animal Health, East Hanover, $\mathrm{NJ}$ ).

Eight birds had maggots, so the treatment for these birds was to check the vents at least three times daily for the first day or two in order to remove any maggots that were missed or subsequently hatched. Fourteen birds had very irritated or partially prolapsed vents, and these were checked three times daily and Preparation- $\mathrm{H}^{\circledR}$ applied to the vents as needed. The irritated skin continued for up to two weeks for individual waterfowl.

Unfortunately, many waterfowl arrived in midmolt with little ability to preen and maintain feather condition, and thus had poor water-proofing. Many mallards were soaked to the skin after swimming only 5 to 10 minutes. These birds were given a warm air blower (pet dryer) after each swim to encourage preening and hasten drying.

Once the birds began to self-feed, the number of gavage feedings was reduced. At time of reduced gavages, many of the birds would start to lose rather than gain weight. All shorebirds were weighed daily and all waterfowl were weighed every other day in order to catch weight loss before it became too serious. Fecal smears and flotations were conducted on any birds that had consistent weight loss after starting to self-feed, and most of these birds were found to have Giardia spp. Although wild waterfowl and shorebirds often carry giardia asymptomatically, it appeared to be causing a problem with these birds presumably because the botulism and stress compromised the immune system.

Twenty-two birds were treated for giardia with metronidazole at a dosage of $30 \mathrm{mg} / \mathrm{kg}$ twice daily for seven days. During this time, tubs were disinfected with bleach immediately after any waterfowl diagnosed with giardia swam in them. Birds with giardia were housed together; group fecal exams were conducted following treatment and second rounds of treatment were administered as necessary.

\section{OR IS IT BOTULISM?}

Laboratory Results. Meanwhile, although the conditions and clinical signs were right for an avian botulism event, a higher than normal mortality rate was occurring, and the event was lasting much longer than usual. In early August, carcasses of an American black duck, two mallards, and one double-crested cormorant (Phalacrocorax auritus) were sent from Poplar Island to the National Wildlife Health Center (NWHC) in Madison, WI. All four were found to be emaciated with no obvious cause of death seen at necropsy. One mallard screened positive via matrix RT-PCR (reverse transcriptase polymerase chain reaction) for avian influenza (AI) virus (non-H5, non-H7 subtype); however, this likely represented a low-pathogenic strain of AI that occasionally is detected among North American waterfowl and was not clinically significant. All four birds also screened negative for Newcastle Disease virus, cultured no significant bacteria from the livers or colons, and most importantly, all four tested negative for botulism.

Testing for botulism involves taking serum from the affected bird and injecting it into two sets of mice: one set that has been given a botulism antitoxin and one that has had no treatment; if botulinum toxin is present, the group of untreated mice develops paralysis and/or dies. On the same day the results were received from the NWHC, the freshwater algal toxin microcystin was detected at $6000 \mathrm{ug} / \mathrm{L}$ in water samples sent to GreenWater Lab/CyanoLab (Palatka, FL).

\section{Harmful Algal Blooms (HABs) and Their}

Effects. By the end of August, the algal bloom in Cell 6 was more extensive than earlier in the event, extending 30 meters out from the shoreline around most of the cell. An increase in nutrients in the water, combined with suitable water temperatures, can cause an "algal bloom" or rapid proliferation of blue-green algae (Cyanobacteria), which also can produce toxins (phycotoxins known as cyanotoxins) under these environmental conditions. Cyanotoxins are classified as either neurotoxins or hepatotoxins; the toxin in this event, microcystin, is a known hepatotoxin, causing acute liver damage and death.

Not all the harmful effects of algal blooms are related directly to toxin production, but rather to the depleted dissolved oxygen concentrations in water caused by the rapid algal growth and decay. Large blooms also may occlude sunlight or may cause direct physical damage to fish gills, leading to large-scale die-offs (Creekmore 1999). These events then may produce an environment conducive to botulism: the dead plants and fish provide additional nutrient for Clostridium to activate and grow, resulting in a cycle of algal bloom and botulism.

Ingested microcystins are absorbed by the GI tract and carried to the liver, causing structural damage to hepatocytes, resulting in tissue necrosis, and accumulation of blood in the liver. Hypovolemic 
shock or hepatic insufficiency may cause death within a few hours of ingestion. Microcystins also inhibit protein phosphatase activities in the liver, leading to the induction of hepatic neoplasias (Landsberg et al 2007).

Clinical signs associated with microcystin toxicity include regurgitation of algae, diarrhea, reduced responsiveness and activity, and death. On necropsy, affected birds may have enlarged livers with areas of necrosis and hemorrhage.

A presumptive diagnosis may be made based on the presence of an algal bloom in conjunction with a die-off, and supportive clinical and pathologic findings. Analysis of the upper gastrointestinal tract contents or tissues of affected birds for microcystins may be made by some laboratories using enzyme linked immunosorbant assays (ELISAs) or high performance liquid chromatography (HPLC), but these tests are not widely available (Landsberg et al 2007). As with many newer tests, there are no established toxic thresholds for many wildlife species. Algal blooms are often short-lived, so water samples should be collected as quickly as possible once animals are affected.

Although no liver lesions were found in the birds initially sent to the NWHC, a presumptive diagnosis of harmful algal bloom (HAB toxicosis) was made based on the presence of the algal bloom, microcystins found in the water, and the negative botulism tests.

More Laboratory Work. On 5 September, a conference call was held between staff from Tri-State, USFWS, MES, MD DNR, NWHC, Southeast Cooperative Wildlife Disease Studies, and University of Pennsylvania, School of Veterinary Medicine (UPENN). At this point, over 400 birds had been collected; over 132 live birds had been submitted to Tri-State for rehabilitation, with 36 percent of those birds surviving. Plans were made to send additional samples to test for botulism, microcystin levels, heavy metals, and organic chemicals.

Blood, liver, gastrointestinal contents, and water samples were submitted to the toxicology laboratory at the University of Pennsylvania (Kennett Square, PA) for analysis by Liquid Chromatography/Mass Spectroscopy. The one blood sample tested was negative for microcystin and for the freshwater algal toxins anatoxin and nodularin. Twelve of fourteen liver samples, however, were positive for microcystin at levels consistent with or exceeding those associated with other reported avian and mammalian mortalities in the United States (Carmichael and Li 2006; Miller et al 2010; van der Merwe et al 2012; CSU 2003). One water sample and five of seven samples of gastrointestinal contents also were positive for microcystin.

Two more mallards, a semi-palmated sandpiper (Calidris pusilla) and an American green-winged teal (Anas crecca carolinensis) carcasses were sent to the NWHC after the conference call. These specimens were in fair to excellent nutritional condition with no significant lesions. The three ducks tested positive for type $\mathrm{C}$ botulism. Brain cholinesterase activity was within normal limits for all four specimens. Liver lead levels were below detectable limits for all but one mallard (slightly elevated at $0.40 \mathrm{ppm}$ ). No significant bacteria were cultured and screening for $\mathrm{AI}$ and Newcastle disease virus were negative for the three ducks. Two final mallards sent to NWHC at the time of the second peak of dead birds (carcasses found in Cell 3) tested positive for type $\mathrm{C}$ botulinum toxin.

\section{RELEASE CONDITIONING AND EVALUATION}

Once the birds had begun walking and self-feeding well, were gaining or at least maintaining weight, and in the case of some, flying well, they were evaluated for going outside. Birds being treated for giardia were kept inside until their treatment was over, just for ease of twice-daily capture for medicating, and so their droppings would not contaminate outdoor enclosures. An exception had to be made for a group of eight affected mallards who had to be moved outside due to limited space indoors.

Birds with poor water-proofing also were kept inside until they could at least be swum without being put under a blower afterwards. However, in order to minimize stress, some waterfowl were moved outside while the water-proofing was still quite poor. These birds were placed in a cage with a shallow pool and poultry brooders to assist with drying and prevent hypothermia. These particular birds required two or more weeks in outside pools before release could even be considered.

Several different enclosures were used for housing waterfowl, though only one had a built-in pool (additional cages with built-in pools were under construction at the time of this event). The various cages were provided with plastic wading pools that were dumped out and scrubbed almost every day. These enclosures also had wood decking that was partially cover with Dri-Dek ${ }^{\mathrm{TM}}$ panels (Dri-Dek Co., Sarasota, FL) and AstroTurf ${ }^{\mathrm{TM}}$ (AstroTurf LLC, White Plains, NY) to help maintain the condition of the birds' feet. Despite these efforts, some waterfowl that were not waterproof developed foot sores from the wood decking (these birds were spending less time in the water). This problem was treated by applying a thick layer of 
New-Skin ${ }^{\mathrm{TM}}$ (Medtech, Jackson, WY) to the feet every three days when the birds were weighed and evaluated.

Evaluating and Banding Birds. Shorebirds moved outside stayed in songbird cages equipped with sand covered bottoms. Bundles of fresh and dried reeds, pieces of driftwood, and good-sized shallow glass or faux rock dishes in which they could forage were provided in the cages. Most shorebirds, once moved to an outdoor enclosure, were soon ready for release. This was particularly important for least sandpipers (Calidris minutilla), semi-palmated sandpipers, and pectoral sandpipers (Calidris melanotos) who were mid-migration and could not afford to be delayed any longer than necessary. As soon as they started flying well and were in good condition, they were evaluated for release. Each bird was weighed, examined for waterproofing, and mentation and body condition; those determined ready for release were banded and boxed for transport to an appropriate release site.

Release Site Decisions. Waterfowl were released at multiple locations in Delaware and Maryland. Because the event continued for several weeks, the birds were not released near Poplar Island. Several volunteers and staff members located good waterfowl habitat with remote ponds and rivers; these were the predominant release locations. One of the green-winged teals became a bit of a celebrity when he was released at the 75th Anniversary celebration of Bombay Hook National Wildlife Refuge.

Release sites for shorebirds were chosen in a similar manner, making sure the sites had good feeding habitat, i.e., low ponds and marshlands, where other shorebirds had been spotted.

Overall Numbers. Over the course of the 14-week event, the total number of individual animals collected was 777: 564 dead (556 birds and 8 mammals) and 213 live, representing a total of 35 different species (25 species presented live to Tri-State). The survival rate for birds admitted for rehabilitation and surviving initial stabilization and treatment was 56 percent, considerably lower than for previous botulism events.

During the latter part of this event, in early October, a sick surf scoter (Melanitta perspicillata) was dropped off at the home of a Tri-State volunteer in Lewes, DE. This bird presented with the same clinical signs of Stage I botulism (stumbling, matted urates around vent, emaciated) and was provided with supportive care. The bird died overnight and tissues sent to the University of Pennsylvania toxicology laboratory tested positive for microcystins. Although the lack of information regarding this bird's point of capture makes it impossible to say for certain, the bird likely was not associated with the event on Poplar Island. It is, however, another example of a $\mathrm{HAB}$, and one that possibly was related to botulism.

The occurrence of HABs in conjunction with avian botulism events is not a new phenomenon. Both events occur under the same environmental conditions and have been observed in South Africa (Jan Myburgh, personal communication, 2010), Australia (McComb and Davis 1993), Canada (Murphy et al 2000; Park et al 2001), and the US (Cohn 2000; Johnson and Carpenter 2010; Carmichael and Li 2006; Driscoll et al 2002). Because limited diagnostics for microcystins are available, and funding for such diagnostics in wildlife is not readily available, the probability is high that many birds considered to have died from botulism, instead may have died from microcystin toxicosis-or both.

\section{CONCERNS AND LESSONS LEARNED}

Prompt removal of carcasses from the area may help reduce the load of toxin in the environment and prevent possible secondary exposure by scavengers.

It's Not Always What You Think It Is! While the initial diagnosis of botulism did end up being correct for some if not all birds, the situation was complicated by the concurrent presence of microcystins. It proved advantageous to take additional precautions and submit samples for laboratory confirmation, even when the clinical presentation was strongly suggestive of botulism.

Human Health Concerns. Although the type $\mathrm{C}$ botulism toxin that some of the birds had is not thought to be transmissible to humans, the microcystin toxin certainly is. Blue-green algae has been reported to cause contact dermatitis and gastroenteritis in people (Hooser and Talcott 2001). Gloves were worn initially when handling the birds to prevent damage to their waterproofing; after the diagnosis of microcystins, gloves continued to be worn for personal protection. It paid to be overly cautious, even in an event where this level of protection normally might not be required.

Collect and Bank Samples. Now that testing for microcystins is more readily available, it would be nice to have samples from previous known botulism events in the Delaware Bay and Dover areas to see if these toxins played a contributing role, as they appeared to do in this Chesapeake Bay event. 
Value of Having Pre-set Protocols. Having protocols that give estimated dosing amounts of fluid and medication were helpful in reducing the time spent handling the birds and calculating medication and fluid requirements. Protocols for treating each stage of botulism and keeping the birds moving through the rehabilitation process also were extremely helpful when inexperienced staff and volunteers helped with bird care. Written protocols reduced the potential for mistakes and the experienced staff did not have to spend time explaining every detail of bird care to those less skilled. Having a network of volunteers in the area who were willing to make the four-hour round trip to Poplar Island also was invaluable. Without these amazing people, the response would not have been nearly as efficient and effective.

Predator Concerns. While there were no confirmed secondary illnesses in this event, predatory species including bald eagles (Haliaetus leucocephalus) were present in the area and suspected to have fed on carcasses of affected birds. Hazing plans should be included for future events to reduce the potential impact on predatory species.

\section{According to the Literature, Shorebirds} Cannot Be Treated for Botulism. This concept has been disproved in other responses, but the fact has not been published prior to this account. As experienced in this event, although it often was difficult to get shorebirds through the first few days of rehabilitation, they tended to recover very quickly and with few secondary problems. Excluding the shorebirds that were dead on arrival or died prior to the admission exam, the overall survival/release rate for shorebirds in this event was 40 percent. While this release rate is lower than that of waterfowl and gulls for the event (58 percent), it is certainly high enough to justify attempting treatment.

It Takes a Village. The authors wish to thank the staff and volunteers at Tri-State Bird Rescue \& Research, Inc., for making all those trips to Tilghman Island and receiving sick birds for transport to Tri-State. Thanks to all the volunteers who took time from their regular jobs to assist in field surveys collecting sick and dead birds and who made it possible to conduct thorough and efficient field surveys. Thanks to the staff at the Southeastern Cooperative Wildlife Disease Study, National Wildlife Health Center, and University California-Davis for pathology and diagnostics of submitted wildlife. Thanks to Greenwater Laboratories, the Maryland Department of the Environment (MDE) and to Lisa Murphy, VMD, and the staff at the University of Pennsylvania, Department of Pathobiology, School of Veterinary Medicine, for the microcystin evaluation on many of the tissue samples. A very special thanks to MES Environmental Unit staff Michelle Osborne, Claire Ewing, and Alexa Poynter for their fieldwork in collecting sick and dead birds on a daily basis, stabilizing sick birds, and making it possible to get sick birds to Tri-State as quickly as possible. Lastly, thanks to Chris Dwyer and the US Fish and Wildlife Service's Region 5 Office of Migratory Birds for providing funding for pathology and diagnostics of individual animals and chemical analyses of tissue samples.

\section{LITERATURE CITED}

Carmichael, W., and R. Li. 2006. Cyanobacteria Toxins in the Salton Sea. Saline Systems. 2: 5. Available from: <http://en.youscribe.com/catalogue/reports】and $\llbracket$ theses/knowledge/cyanobacte-

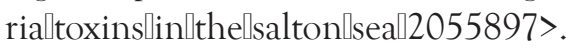

Cohn, J. P. 2000. Saving the Salton Sea. BioScience. 50(4): 295-301.

CSU, Colorado State University, Veterinary Diagnostic Laboratory. 2003. Case 11-024-031 (AFIP 2888659): Pastured Adult, Female, Gelbvieh Bovine. The Armed Forces Institute of Pathology, Department of Veterinary Pathology. Wednesday Slide Conference \#6. 22 October.

Creekmore, L. H. 1999. Algal Toxins. Field Manual of Wildlife Diseases. (M. Friend and J. C. Franson, editors). USDI, USGS: Washington, D.C. Pps. 271-281. Also available at: 〈http://www.nwhc. usgs.gov/pub_metadata/field_manual/chapter_36. pdf $>$.

Cubas, Z. S. 1993. Natural Diseases of Free円ranging Birds in South America. Zoo and Wild Animal Medicine: Current Therapy 3. (Fowler, M. editor) W. B. Saunders, Co: Philadelphia, PA.

Driscoll, C. P., P. C. McGowan, E. A. Miller, and W. W. Carmichael. 2002. Proceedings of the Southeast Fish and Wildlife Conference. Baltimore; Case Report: Great Blue Heron (Ardea herodias) Morbidity and Mortality Investigation in Maryland's Chesapeake Bay. 24 October 2002.

Forbes, N. A. 1996. Nervous Diseases. Manual of Raptors, Pigeons and Waterfowl. (P. H. Benyon, editor) Iowa State University Press: Ames, IA.

Gomez, H. F., R. Johnson, H. Guven, P. McKinney, S. Phillips, F. Judson, and J. Brent. 1995. Adsorption of Botulinum Toxin to Activated Charcoal with a Mouse Bioassay. Annuals of Emergency Medicine. 25(6): $818-822$. 
Hooser, S. B. and P. A. Talcott. 2001. Blue-green Algae. Small Animal Toxicology. (M. E. Peterson and P. A. Talcott, editors). W. B. Saunders Company: Philadelphia, PA.

Hunter, B. F., W. E. Clark, P. J. Perkins, and P. R. Coleman. 1970. Applied Botulism Research Including Management Recommendations: A Progress Report. California Dept. Fish \& Game: Rancho Cordova, CA. 87 Pp.

Jensen, W. I. 1981. Evaluation of Coproexamination as a Diagnostic Test for Avian Botulism. Journal of Wildlife Disease. 17(2): 171-176.

Johnson, T. J., and S. R. Carpenter. 2010. Influence of Eutrophication in Disease in Aquatic Ecosystems. Infectious Disease Ecology: Effects of Ecosystems on Disease and of Disease on Ecosystems (R. S. Ostfeld, F. Keesing, V. T. Eviner, editors). Princeton University Press: Princeton, NJ.

Jones, B. 1984. Rehabilitation of Birds Affected by Botulism in a Salt Marsh. Wildlife Rehabilitation: Proceedings of the New York State Wildlife Rehabilitation Seminars. (M. Forness, editor). Landsberg, J. H., G. A. Vargo, L. J. Flewelling, F. E. Wiley. 2007. Algal Biotoxins. Infectious Diseases of Wild Birds. (N. J. Thomas, D. B. Hunter, and C. T. Atkinson, editors). Blackwell Publishing: Ames, IA.

McComb, A. J., and J. A. Davis. 1993. Eutrophic Waters of Southwestern Australia. Fertilizer Research. 36 (2): 105-114.

Miller, M. A., R. M. Kudela, A. Mekebri, D. Crane, S. C. Oates, et al. 2010. Evidence for a Novel Marine Harmful Algal Bloom: Cyanotoxin (Microcystin) Transfer from Land to Sea Otters. PLoS ONE. 5(9). Available from: <http://www.plosone.org/article/ info:doi/10.1371/journal.pone.0012576>.

Murphy, T., A. Lawson, C. Nalewajko, H. Murkin, L. Ross, K. Oguma, and T. McIntyre. 2000. Algal Toxins-Initiators of Avian Botulism? Environmental Toxicology. 15: 558-567.

NOAA. National Oceanic and Atmospheric Administration, National Climatic Data Center. Accessed weather for Poplar Island, MD in August 2012 and average temperatures and rainfall for the month of August in Poplar Island. Available online at: <http://www.ncdc. noaa.gov>.

Park, H., M. Namikoshi, S. M. Brittain, W. W. Carmichael, T. Murphy. 2001. [D-Leu(1)] microcystin-LR, a New Microcystin Isolated from Waterbloom in a Canadian Prairie Lake. Toxicon. 39(6): 855-862.
Rocke, T. E., and T. K. Bollinger. 2007. Avian Botulism. Infectious Diseases of Wild Birds. (N. J. Thomas, D. B. Hunter, and C. T. Atkinson, editors). Blackwell Publishing: Ames, IA.

Rocke, T. E., and M. Friend. 1999. Avian Botulism. Field Manual of Wildlife Diseases. (M. Friend and J. C. Franson, editors). USDI, USGS, Washington, D.C. Pp. 271-281. Also available at: <http://www. nwhc.usgs.gov/pub_metadata/field_manual/ chapter_38.pdf>.

Segner, W. P., C. F. Schmidt, and J. K. Boltz. 1971. Minimal Growth Temperature, Sodium Chloride Tolerance, $\mathrm{pH}$ Sensitivity and Toxin Production of Marine and Terrestrial Strains of Clostridium botulinum type C. Applied Microbiology. 22: 1025-1029.

van der Merwe, D., L. Sebbag, J. C. Nietfeld, M. T. Aubel, A. Foss, and E. Carney. 2012. Investigation of a Microcystis aeruginosa cyanobacterial freshwater harmful algal bloom associated with acute microcystin toxicosis in a dog. Journal of Veterinary Diagnostic Investigation. 24: 679. (N.

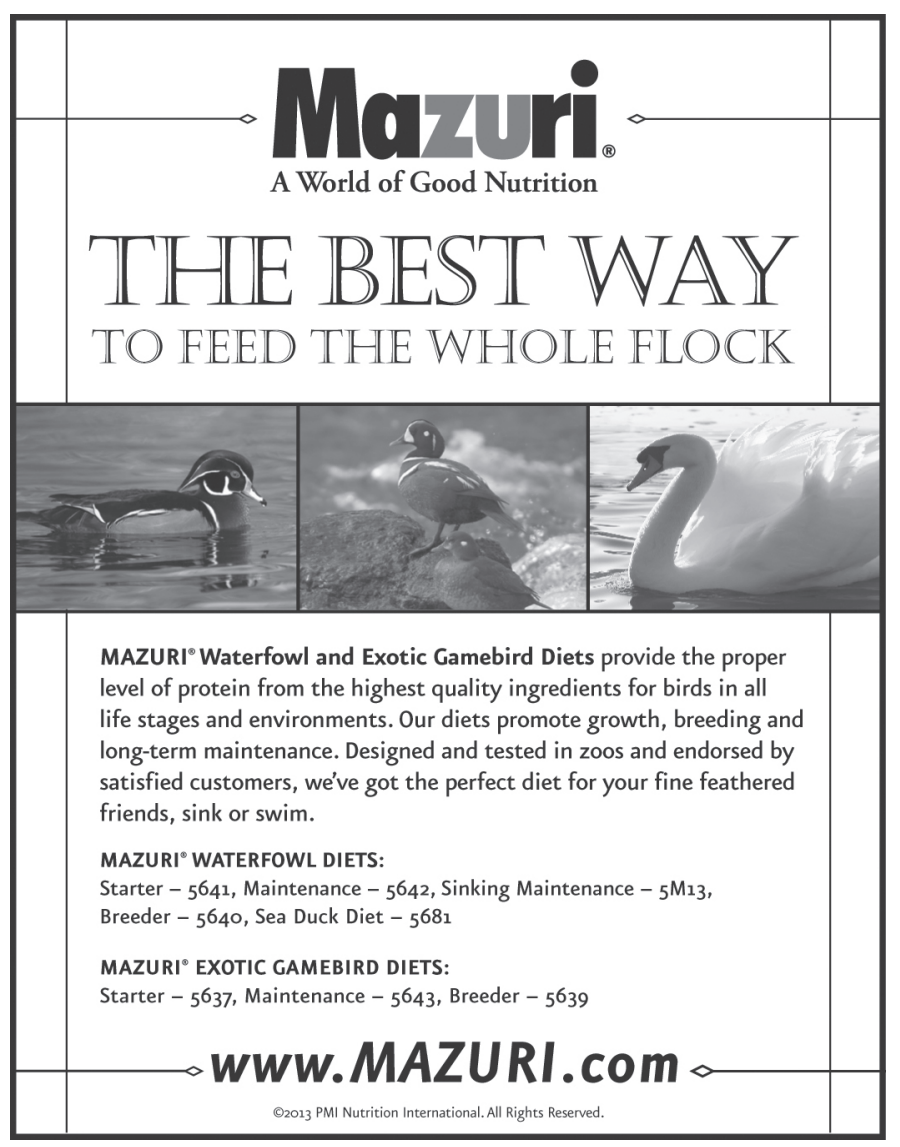

